\title{
Effect of a Contact-Based Education Intervention on Reducing Stigma Among Community Health and Care Staff In Beijing, China: Pilot Randomized Controlled Study
}

\section{Wufang Zhang}

Peking University Sixth Hospital https://orcid.org/0000-0003-0221-0012

Claire Henderson

King's College London

Erla Magnusdottir

King's College London

\section{Weiran Chen}

Peking University Sixth Hospital

\section{Ning Ma}

Peking University Sixth Hospital

Hong Ma ( $\nabla$ mahongbjmu@163.com )

Peking University Sixth Hospital

Graham Thornicroft

King's College London

Research article

Keywords: Stigma, social contact, education, intervention, mental illness

Posted Date: February 11th, 2021

DOI: https://doi.org/10.21203/rs.3.rs-223063/v1

License: (c) (i) This work is licensed under a Creative Commons Attribution 4.0 International License. Read Full License

Version of Record: A version of this preprint was published at Asian Journal of Psychiatry on April 1st, 2022. See the published version at https://doi.org/10.1016/j.ajp.2022.103096. 


\section{Abstract}

Background Increasing evidence suggests that the stigma associated with mental illness is a powerful barrier to accessing mental health care worldwide. Consistent findings in high-income countries have shown that contact with people with mental illness is the most effective intervention to reduce stigma. However, little evidence is available at present on how to reduce stigma in low- and middle-income countries, including China. In this context the aim of this paper is to report the findings of a pilot study to assess the feasibility of an intervention to reduce stigma among primary care and community healthcare staff in Beijing, China through a contact-based education intervention.

Methods Community healthcare staff were recruited including primary health care staff and community administrators. They were randomly assigned to: (i) "education only" group, a lecture-based education (the control condition); or (ii) "education and contact" group, lectures plus contact with people with mental illness (the experimental condition). Each participant completed an assessment of mental health stigma related: knowledge (mental health knowledge schedule, MAKS); attitudes (mental illness: clinicians' attitudes scale, MICA-4); and behavior (Reported and intended behavior scale, RIBS) before and after the intervention, with follow up at 1 month and 3 months after the intervention.

Results A total of 121 community staff were recruited, including 67 workers in primary health care and 54 community workers. Both "education only" group and "education and contact" group showed improved knowledge after the intervention, MAKS scores increased by $1.77 \pm 3.15$ VS $2.46 \pm 2.49$, respectively. There was no between-group difference in MAKS score. The "education and contact" group showed a significantly greater improvement for MICA and RIBS score than the "education only" group: the MICA score decreased by $4.07 \pm 8.38$ VS $8.41 \pm 7.48(p=0.003)$, and the RIBS score increased by $2.28 \pm 3.89$ VS $4.57 \pm 3.53(p=0.001)$, in the "education only" and the "education and contact" groups respectively, but the between group differences disappeared at 1 month and 3 months follow-up points. The positive effects on behaviour in both groups were sustained at 3 months.

Conclusion The intervention to reduce stigma among the primary and community healthcare staff through a contact-based education intervention was feasible in Beijing. There is initial evidence from this study that contact based education with people with mental illness (including using recovery stories) appears to be an effective intervention for stigma-related attitudes and behavior. This approach needs to be replicated with longer follow-up to examine sustained changes over time.

Trial Registration: ISRCTN13779136, https://doi.org/10.1186/ISRCTN13779136, Effect of a contact-based education intervention on reducing stigma among community health and care staff in Beijing, China

\section{Background}

Providing mental health care in China is crucial in order to close the mental health treatment gap. The WHO mental health action plan aimed to increase mental health service coverage by $20 \%$ by the year $2020[1]$. Understanding how to improve mental health service provision in China and India, as the two most populous 
countries in the world, is vital if ambitious global mental health and sustainable development goals are to be met [2].

In recent years China has made great progress in strengthening mental health systems. In 2004, China officially placed mental health services within the public health system, and the national government then launched the National Continuing Management and Intervention Program for Psychosis[3]. This program has contributed to improving care for patients with severe mental disorders through increasing provision of treatment and by integrating hospital and community services designed to provide continuity of evidencebased care.

In 2015, an updated program named 'National Mental Health Integrated Management Pilot Project' was launched by five governmental ministries of China (The Central Comprehensive Management Office, Ministry of Civil Affairs, Ministry of Public Security, Human Resources and Social Security, and National Health and Family Planning Commission) and the China Disabled Persons' Federation (CDPF). One of the most important aims of this new program was to establish community integrated service teams which consisted of officers from the community committee, Civil Affairs and CDPF, and primary health care staff [4]. This method of task shifting where non mental health professionals are providing mental health services has been promoted globally as an important way to rapidly close the service gap[5]. Although there has been significant progress in the mental health field in China there are still challenges. Treatment coverage is still very low, especially for people with common mental disorders, and significant disparities still exist in services provided between urban and rural areas[2]. In order to move forward it is essential to look at how these newly formed integrated mental health teams can best meet the needs of patients and their families.

There is preliminary work that suggests that stigma among community mental healthcare staff may be an important barrier and can threaten the success of China's mental health programs[6]. Stigma can be thought to be composed of issues related to knowledge (ignorance), attitudes (prejudice) and behaviour (discrimination)[7,8]. Stigma is commonly experienced by people with mental illness all over the world[9]. In China this has also been found to be the case[10,11]. Scholars have suggested that mental health stigma might be particularly deep rooted in China due to cultural factors, resulting in people often opting to conceal their illness[12]. Therefore seeking help may be especially difficult in China and it is important that healthcare staff be a source of support and not of stigma, but that is not always the reality at present. It has been shown that negative attitudes towards people with mental illness are commonly found among primary and secondary healthcare staff [9,13-15]. It appears that stigma among health professionals is associated with reluctance to investigate physical complaints [16], or to refer for specialist treatment [17], and stigma can act as a barrier to engagement in treatment for both mental and physical disorders. These problems will affect the quality of care received and can also contribute to the reduced life expectancy of people with severe mental illnesses[18].

Having contact with someone with mental illness has been found to be an effective stigma intervention[19], and studies have found that contact interventions, such as combining professional training with presentations by individuals with personal experiences of mental illness, to be more effective then training alone[20]. Contact based education has also been found to be effective in reducing stigma among different groups including health professionals [21], police [22] and young people[23]. Studies in China have shown 
that healthcare staff who report greater quality of contact with people with mental illness subsequently report less stigma. However most of the research around contact based interventions comes from western countries and this has not been sufficiently tested in China[6,24,25].

The aims of this pilot study are to: (1) undertake an assessment of the feasibility of an intervention to reduce stigma among primary health care staff and community staff in China through a contact intervention; and (2) to test the hypothesis that an "education and contact" (experimental) intervention would be more effective at reducing stigma than an "education only" (control) intervention, using with stigmatising attitudes as primary outcome. To the best of our knowledge there are no previous studies that have directly examined contact-based education as an intervention to reduce stigma for such health care and community staff in mainland China.

\section{Methods}

\section{Study Design and participants}

This randomized controlled trial (RCT) was conducted in four localities in three districts (Chaoyang, Haidian and Fangshan) in Beijing, China. Staff from primary care centers, community committees, Civil Affairs and the China Disabled Persons' Federation in the four localities were referred to the study if they: (a) were aged 18-60; (2) had more than one year work experience; and (3) were literate. Participants were told prior to participating that the intervention was aimed at reducing mental illness stigma. They were randomized to either the "education only" (control) or "education and contact" (experimental) group in order to compare the effect of lectures about mental illness or lecture plus contact with patients with a clinical diagnosis of schizophrenia or bipolar disorder. The intervention took place between December 2018 and Mar 2019. Six sessions were carried out with 18-25 participants in each session. The study was approved by the Peking University Institutional Review Board (Year 2017,No. IRB00001052-16077).

Each site had a project coordinator who issued a notice about the programme on mental illness and stigma, and invited colleagues who were interested to sign up, both in the facilities and by notifying potential participants by social media. All potential participants were informed about the project and all participants signed a written, informed consent sheet.

\section{Randomization And Sample Size Randomization}

Participants had an equal probability of being assigned to the two study groups.. Using a computergenerated randomization a list was compiled through simple randomization, participants were randomly assigned (ratio 1:1) to the two groups by an independent third party. To ensure the concealment of allocation, this third party used a protected computer database for the randomization list. Those in the "education only" group received the lecture alone without contact, while those in the "education and contact" group were invited also to stay for the contact intervention session that followed immediately after this. 


\section{Sample size}

In a previous trial in China, the mean score of MICA decreased from $47.92 \pm 8.63$ to $43.53 \pm 9.61$ after mental health training[26]. Based on this difference, it was calculated that at least 55 participants were required in each group to achieve a significance level of $5 \%$ (two sided) and a power of 0.70 .

\section{Interventions}

\section{Control condition}

The lecture was divided into three parts: (1) a brief introduction of the classification and treatment of mental disorders, as well as community mental health services in China; (2) details of the prevalence rates, main symptoms, illness course, principles of treatment, effect of treatment and extent of recovery of schizophrenia and bipolar disorders, as well as introducing historical famous people who suffered with these two disorders. (3) an introduction to mental illness related stigmatization. MH held the first two parts of the lecture while part 3 was led by WZ. The lecture took approximately 2 hours. Participant were encouraged to ask questions during the lecture.

\section{Experimental condition}

The experimental condition also included the lecture described above and in addition there was a session on patient recovery stories (the social contact element). For the "education and contact" group, this contact part was composed of hearing both in person recovery stories told directly by patients with a clinical diagnosis of schizophrenia or bipolar disorder, and watching recovery stories recorded in the form of a film. Selected recovered patients, on the basis of the "recovery story checklist" provided by $\mathrm{CH}$, wrote their personal recovery narratives, including reference to their symptoms, treatment and recent experiences. The stories of two recovered patients were adapted and converted into two short films, each film of about 4 minutes. In each contact session, two or three recovered patients participated and shared their own experience of recovery. After that, the film which included the two recorded recovery stories were played (one of a person with a diagnosis of schizophrenia and one with bipolar disorder). This contact session lasted about 1 hour. Participants were encouraged to communicate with the patients. Full details of the experimental and control condition interventions are available from the corresponding author on request.

\section{Measures}

\section{Mental health related knowledge}

Mental health related knowledge was measured using the Mental Health Knowledge Schedule (MAKS), which consists of 12 items and each item was rated on a 5-point Likert scale which ranged from strongly disagree to strongly agree [27]. The overall test-retest reliability of MASK score was 0.71 (Lin's concordance statistic). Item retest reliability, based on a weighted kappa, ranged from 0.57 to 0.87 , suggesting moderate to substantial agreement between the 2 time points. The overall internal consistency among items 1 to 6 was 
moderate (0.65). MAKS is a brief instrument which can be used in conjunction with other scales related with attitudes and behaviour.

\section{Mental health related attitudes}

The Mental illness: Clinicians'Attitudes (MICA) was used to assess participants attitudes towards people with mental illness [28]. The scale consisted of 16 items and a 6-point scale which ranged from strongly agree to strongly disagree. A higher score indicated a higher level of negative stigma-related mental health attitudes. The MICA scale showed good internal consistency (alpha = 0.79). The test-retest reliability (concordance) was 0.80 (95\% Cl: $0.68-0.91)$. The Chinese version of MICA, which has been tested also shows good validity and reliability (Cronbach alpha $=0.72)[29]$.

\section{Intended behavior}

Reported and Intended Behaviour Scale (RIBS)[30] was used to measure intended behavior, which was derived from the Star Social Distance Scale[31]. We use four items-living with, working with, living nearby and continuing a relationship with someone-to assess the desire of future contact with people with mental illness. A higher score indicates less desire for social distance. The total RIBS score was standardised. Studies showed that the overall test-retest reliability of total RIBS score was 0.75 (Lin's concordance statistic). Item retest reliability ranged from 0.62 to 1.0 , indicating moderate to substantial agreement between time points. The overall internal consistency (Cronbach's alpha ) among the subscale items was 0.85[30]. The Chinese version of RIBS has been shown to have strong internal consistency (Cronbach alpha $=0.82)$ and test-retest reliability $(r=0.68)[32]$.

\section{Statistical Analyses}

All of the statistical analyses were performed using the Statistical Package for Social Sciences (SPSS), Version 26.0 (SPSS Inc., Chicago, Illinois). The continuous variables were described using summary statistics, such as the means and standard deviations. The categorical variables were described using frequencies and percentages. The baseline characteristics of each group were compared using a t-test for the continuous variables and the chi-square test for the categorical variables.

The outcome measures were the MAKS, MICA and RIBS scores. Firstly, the change in the MAKS, MICA and RIBS total scores (after intervention vs baseline) was calculated for each participant. Secondly, the main strategy involved repeated-measures analysis of variance (ANOVA). For the dependent variables, 4 time points were used as the within effect, and group was used as the between effect. If the time-by-group interaction effect was significant, then multivariate analysis of variance (MANOVA) was applied to examine the group differences at post intervention, 1 month and 3 months. Finally, one-way repeated-measures analysis of variance was used to see the differences in outcomes among the different assessment points after intervention. Significance was set at $p<0.05$ using a 2 -sided test.

\section{Results}




\section{Socio-demographic data}

The trial profile is shown in the CONSORT chart Fig. 1. A total of 121 community staff were recruited between October and December 2018, including 67 workers in primary health care and 54 community workers. 1 participant was lost at 1 month follow up in the "education only" group because of illness, but had recovered when 3 months follow up was conducted. 3 participants were lost at 3 months follow up in the "education and contact" group since they could not be contacted due to work engagements. The number of participants in the "education only" group at the assessment time points were $60,60,59$, and 60 , respectively and in the "education and contact" group were $61,61,61$, and 58 respectively.

The assessment time points were: pre-intervention (baseline), post-intervention, 1 month after intervention, and 3 months after intervention. All the assessments were carried out between December 2018 and March 2019. At baseline, there was no statistical difference between the two groups in gender distribution, education, marital status, fertility status (Table 1), more than $60 \%$ were female, more than $70 \%$ were married and had children. The mean age and years of work were different between the two groups. Participants in "education only" group were slightly older than "education and contact" group (39.85 \pm 7.71 VS $36.7 \pm 7.61, p$ $=0.026)$, and had somewhat longer work experience ( $16.72 \pm 8.03$ VS $13.13 \pm 8.16, p=0.017)$. There was a significant correlation between age and work experience $(r=0.909, p<0.001)$. In the following analysis, age was used as a control variable when comparing the differences between the two groups. 
Table 1

Socio-demographic characteristics of the study participants

\begin{tabular}{|lllll|}
\hline Characteristics & $\begin{array}{l}\text { Education only } \\
(\mathbf{n}=60)\end{array}$ & $\begin{array}{l}\text { Education and contact } \\
(\mathbf{n}=61)\end{array}$ & $\mathbf{t} / \mathbf{X} \mathbf{2}$ & $\boldsymbol{P}$ \\
\hline Gender, $\mathrm{n}(\%)$ & & & 2.204 & 0.100 \\
Male & $20(33.33)$ & $13(21.31)$ & & \\
Female & $40(66.67)$ & $48(78.69)$ & & \\
\hline Marital status & & & 7.032 & 0.071 \\
Single & $6(10.00)$ & $15(24.59)$ & & \\
Married & $50(83.33)$ & $44(72.13)$ & & \\
Divorced & $4(6.67)$ & $1(1.64)$ & & \\
Widowed & $0(0)$ & $1(1.64)$ & 1.546 & 0.282 \\
\hline Have child & & & & \\
No & $11(18.33)$ & $17(27.87)$ & & \\
Yes & $49(81.67)$ & $44(72.13)$ & 2.261 & 0.026 \\
\hline Age, year: mean (SD) & $39.85(7.71)$ & $36.7(7.61)$ & 0.309 & 0.758 \\
\hline Education, year: mean (SD) & $15.00(2.08)$ & $14.87(2.62)$ & 2.425 & 0.017 \\
\hline Years of working, year: mean (SD) & $16.72(8.03)$ & $13.13(8.16)$ & & \\
\hline
\end{tabular}

\section{Stigma related knowledge}

At baseline, the average MAKS scores were essentially identical: 22.38 and 22.23 in "education only" and "education and contact" group respectively. There was no statistical difference between the two groups at baseline with age as a covariate $(F=0.011, p=0.918)$. After intervention, The MAKS score increased significantly in the "education only" group with $1.77 \pm 3.15$ (paired t test, $t=3.758, p<0.0001$ ); the "education and contact" group score also increased significantly with $2.46 \pm 2.49$ (paired t test, $t=8.781, p<0.0001$ ).

Repeated-measures ANOVAs on the MAKS scores showed a main effect of time $(F=23.502, p<.001)$, but there was no significant time-by-group interaction effect $(F=0.777, p=0.507)$ or group effect $(F=0.061, p=$ $0.805)$, indicating that the two interventions both resulted in significant improvements in knowledge, but with no significant difference between the two groups (Table 2). 
Table 2

Repeated-measures analysis of variance (ANOVA) for MAKS, MICA and MAKS scores by group at four time points.

\begin{tabular}{|c|c|c|c|c|c|c|c|}
\hline \multirow{3}{*}{$\begin{array}{l}\text { Measures, } \\
\text { groups }\end{array}$} & \multicolumn{4}{|l|}{ Mean(SD) } & \multicolumn{3}{|c|}{$\begin{array}{l}\text { Repeated-measures (ANOVA), } \\
p\end{array}$} \\
\hline & Baseline & After & 1 Month & 3 Months & Time & Group & Timexgroup \\
\hline & & intervention & & & & & \\
\hline $\begin{array}{l}\text { MAKS } \\
\text { score }\end{array}$ & & & & & $<.001$ & 0.805 & 0.507 \\
\hline $\begin{array}{l}\text { Education } \\
\text { only }\end{array}$ & $22.38(3.11)$ & $24.15(2.58)$ & $23.68(2.81)$ & $23.95(2.29)$ & & & \\
\hline $\begin{array}{l}\text { Education } \\
\text { and } \\
\text { contact }\end{array}$ & $22.23(2.60)$ & $24.69(2.04)$ & $23.82(2.28)$ & $23.72(2.30)$ & & & \\
\hline $\begin{array}{l}\text { MICA } \\
\text { score }\end{array}$ & & & & & $<.001$ & 0.463 & 0.006 \\
\hline $\begin{array}{l}\text { Education } \\
\text { only }\end{array}$ & $51.73(8.01)$ & $47.67(9.25)$ & $48.41(8.70)$ & $47.22(9.02)$ & & & \\
\hline $\begin{array}{l}\text { Education } \\
\text { and } \\
\text { contact }\end{array}$ & $51.93(6.99)$ & $43.52(9.12)$ & $47.23(7.75)$ & $48.34(8.37)$ & & & \\
\hline $\begin{array}{l}\text { RIBS } \\
\text { score }\end{array}$ & & & & & $<.001$ & 0.061 & 0.006 \\
\hline $\begin{array}{l}\text { Education } \\
\text { only }\end{array}$ & $11.42(3.42)$ & $13.70(4.22)$ & $13.54(3.57)$ & $13.73(3.60)$ & & & \\
\hline $\begin{array}{l}\text { Education } \\
\text { and } \\
\text { contact }\end{array}$ & $11.16(3.17)$ & $15.74(3.20)$ & $14.46(3.52)$ & $14.72(3.35)$ & & & \\
\hline
\end{tabular}

There were no significant differences in the MAKS score among the 3 assessment points after the education in "education only" group (1-way ANOVA, $F=0.323, p=0.724)$. It shows that the improvement of MAKS score observed from pre-intervention to post-intervention were sustained for three months in "education only" group. The MAKS score improvement was not sustained in "education plus contact" group (1-way ANOVA, $F$ $=3.491, p=0.033)$. However, there were no significant differences between the two groups in MAKS score after 1 and 3 months follow-up.

\section{Stigma related attitudes}

The average MICA scores showed no statistical difference between the two groups at baseline, with age as a covariate $(F=0.880, p=0.350)$. After intervention, the MICA scores both decreased significantly in the "education only" and in the "education and contact" group with $4.07 \pm 8.38$ and $8.41 \pm 7.48$ respectively (paired $t$ test, both $p<0.0001$ ). 
Repeated-measures ANOVAs on MICA scores showed a significant effect of time $(F=24.275, p<0.001)$ and time-by-group interaction effect $(F=4.240, p=0.006)$, suggesting an increase over time in both groups and there were group differences. To examine the group differences, MANOVA was applied. The results showed that the "education and contact" group showed a greater decrease in the MICA score compared to "education only" group at post intervention $(F=7.421, p=0.007$, effect size $=0.062)$. However, the between group difference had disappeared in MICA score after 1 month $(F=0.573, p=0.450)$ and 3 months $(F=0.618, p=$ 0.433) follow-up.

There were no significant differences in the MICA score among the different assessment points after intervention in "education only" group (1-way ANOVA, $F=0.366, p=0.694$ ). It suggests that the improvement of MICA score observed from pre-intervention to post-intervention was sustained for three months in "education only" group. However, the MICA score improvement in "education and contact" group was not sustained (1-way ANOVA, $F=5.379, p=0.005)$.

\section{Stigma related intended behaviour}

The average RIBS scores were not statistically difference between the two groups at baseline, with age as a covariate $(F=0.021, p=0.886)$. The increased RIBS scores from baseline to post intervention in both group were $2.28 \pm 3.89$ VS $4.57 \pm 3.53$ respectively $(p<0.0001)$. Repeated-measures ANOVAs on the RIBS scores showed a significant time-by-group interaction effect $(F=4.263, p=0.006)$ and time effect $(F=45.289, p<$ $0.001)$. MANOVA showed that the RIBS scores were significantly higher in "education and contact" group than "education only" group at post intervention $(F=10.830, p=0.001$, effect size $=0.087)$. However, the between group difference was disappeared in RIBS score after 1 month $(F=3.552, p=0.062)$ and 3 months $(F=2.959, p=0.088)$ follow-up.

There were no significant differences in the RIBS score among the different assessment points after intervention in "education only" (1-way ANOVA, $F=0.036, p=0.965)$ and "education and contact" group (1way ANOVA, $F=2.447, p=0.089)$. It shows that the RIBS score improvement was sustained for three months in both groups.

\section{Discussion}

This study is original in that it is the first randomized controlled study including face to face contact with people with lived experience of mental illness for reducing stigma in Chinese community and primary healthcare staff. The results show that the intervention is feasible and can be effective for improving attitudes and behaviours of healthcare and community staff though more needs to be understood in how to sustain improvements longer term.

Findings from the baseline study of both groups showed that the level of stigma related knowledge was low, but post intervention both groups showed improved stigma levels (knowledge, attitudes and behaviours). This suggests the importance of integrated mental health teams receiving appropriate training in relation to mental health and stigma. A recent study from China showed that when more public health elements were added to a training curriculum there was an enhancement in community mental health staff knowledge and improved attitudes and willingness to have contact with people with mental disorders [33]. 
Traditionally in China mental health training is very clinically focused and may omit information on stigma which was included in the lectures received by both groups in this study. For example, a cross sectional survey of 1372 medical students in China found that conventional medical education did little to combat mental illness stigma, and those that had less stigmatizing views rather had more personal experiences such as friends with mental illness or interest in the field of psychiatry[25].

Promisingly, at the initial follow-up immediately post training, the "education and contact" group had greater improvements for both mental health related attitudes and intended behavior (MICA and RIBS scores). However, the difference between the groups in attitudes and intended behaviors did not persist at 1 month and 3 month follow-up. This is consistent with other research that has found contact based interventions to be effective means of reducing stigma in the short term, but which has indicated that there is at present only weak evidence for the longer term effects [34]. Furthermore, a systematic review examining the medium and long term effect of interventions to reduce mental illness based stigma and discrimination did not find evidence that contact was superior to other interventions in the long term[35]. However, some meta-analyses and reviews have found the effect of contact and contact-based education on mental health stigma to be sustained in the long term[36]. In our study, the effects on knowledge, attitude and behaviour in the "education only" group and the effects on behaviour in the "education plus contact" group were sustained at 3 months.

In our study, the improved effects compared to baseline findings on mental health knowledge, attitudes and intended behaviour were sustained at 3 months follow up in the control group (education only). But the improved effects were sustained only for intended behavior at three months follow up in the experimental group (education plus contact).

A number of different reasons may explain why only a short-term additional benefit was observed in the "education and contact" group compared to "education only" group. This may be related to the limited nature of the contact. During the contact session, after the patients finished sharing their recovery story, participants rarely interacted directly with the patients, although they were encouraged to ask questions or comment. Some of the participants told the researchers that they felt much moved by the patients' life stories. These observations suggest that while the contact may have generated empathy towards the patients, it may not have been sufficient to reduce anxiety about having contact, at least in this setting; both may be important for stigma reduction[37]. Further research is needed to identify if the nature of such contact and the duration have an influence on stigma outcomes.

Furthermore, contact based education may be more effective if it takes place in the wider context of an ongoing anti-stigma social marketing campaign at the same time[22]. It has been shown the that media in China can influence healthcare workers' stigmatising views[24]. Therefore a single contact session's impact may be diminished if the wider social and clinical contexts are stigmatizing in nature, as is the case still with Chinese media that tend to focus on negative stories related to mental health.

\section{Strengths And Limitations}


The strengths of this study are its original aims, its methodological design, including the randomized allocation of participants to the two groups, and the high retention for follow-up. A further strength is that the contact intervention included multiple recovery stories delivered both live and through film. All the stories emphasized recovery [21], and by including a variety of different accounts it meant that individual participants might relate better to some stories than to others.

However, this study also has several limitations. Firstly, the sample size was limited by resource constraints and the study may have been underpowered to detect smaller differences at 1 and 3 month follow ups. And it might be important to look more closely at the integrated mental health participants to see if there are any observed differences in relation to intervention depending on characteristics such as sex, age, or healthcare position. Due to the small scale of this pilot study, there needs to be caution in interpreting the results.

Secondly, the impact observed after the contact intervention was only brief, and it is possible that repeated or ongoing contact may be needed for more sustained improved outcomes. Thirdly, participants rarely interacted directly with the patients, suggesting that a more participatory approach will need to be developed for the contact interventions. More efficient ways to promote contact could be explored, such as patients and community staff working together as a team to complete an assigned task. Finally, although the effects on knowledge, attitudes and behavior in "education only" group and the effects on behavior in "education plus contact" group were sustained at 3 months, future studies will require longer follow-up to examine sustained changes over time.

\section{Implications For Research And Practice}

In China there will be increasing reliance on community staff to provide mental health services in the future. The National Mental Health Work Plan of China (2015-2020) proposed that $70 \%$ of rural townships and urban sub-districts form collective management teams for mental health [38]. It is vital to understand how stigma against people with mental disorders can be reduced among these newly formed teams if progress is to be made. Findings from our study are promising in that they show that it is feasible to impact stigma levels of community primary and community health care staff in China, but these results indicate the need for caution against drawing conclusions about the medium and long term effect of a single contact-based intervention.

Future research is needed to further elucidate the optimal exposure-based educational interventions, such as the types of patient, frequency of intervention, content of narrative, and how to encourage better communication between participants and presenters; and to replicate this study with other target population, such as psychiatric professional, and with media staff in the future.

\section{Abbreviations}

MAKS: mental health knowledge schedule; MICA: mental illness: clinicians' attitudes scale; RIBS: Reported and intended behavior scale; WHO: World health organization; CDPF: China Disabled Persons' Federation; RCT: Randomized controlled trial; SPSS: Statistical Package for Social Sciences; ANOVA: analysis of variance; MANOVA: multivariate analysis of variance; 


\section{Declarations}

Ethics approval and consent to participate. The study was approved by the Peking University Institutional Review Board. All participants gave written informed consent.

Consent to publish. All authors approved the final version to be published.

Availability of data and materials. Data can be made available on request. However, sharing of the data may require IRB approval and some access restrictions may apply. Requests may be sent to the corresponding author.

Competing interests. The authors have no competing interest to disclose.

Funding. This study is supported by King's College London - Peking University Health Science Center Joint Institute for Medical Research (PKU2017ZC001-8). GT is supported by the National Institute for Health Research (NIHR) Applied Research Collaboration South London at King's College London NHS Foundation Trust, and by the NIHR Asset Global Health Unit award. The views expressed are those of the author(s) and not necessarily those of the NHS, the NIHR or the Department of Health and Social Care. GT also receives support from the National Institute of Mental Health of the National Institutes of Health under award number R01MH100470 (Cobalt study). GT is supported by the UK Medical Research Council in relation the Emilia (MR/S001255/1) and Indigo Partnership (MR/R023697/1) awards.CH is supported by the UK Department of Health and Social Care, Big Lottery Fund and Comic Relief for the evaluation of Time to Change England, and by the UK Foreign and Commonwealth Office and Comic Relief for the evaluation of Time to Change Global.

Authors' contributions. GT, $\mathrm{CH}$ and HM conceived this work. WC and WZ completed data acquisition and data analysis. NM led the film shooting of the recovery story. $\mathrm{MH}$ and $\mathrm{WZ}$ guided patients to improve recovery stories. WZ and HM WZ, CH, EM, WC, NM, HM and GT provided critical comments related to the interpretation of study findings. WZ and EM led on drafting the manuscript with subsequent iterations refined by $\mathrm{GT}, \mathrm{CH}, \mathrm{NM}, \mathrm{WR}$ and $\mathrm{HM}$. WZ, $\mathrm{CH}, \mathrm{EM}, \mathrm{WC}, \mathrm{NM}, \mathrm{HM}$ and GT approved the final version to be published. The authors read and approved the final manuscript.

Acknowledgements. We gratefully acknowledge Changchun Zhang Dr, Vice Director of Fangshan Psychiatric Hospital, Jing Wang MS, Director of Health Department, Malianwa Street, Haidian District, Mingyin Hai Dr, Vice Director of Balizhuang Community Health Service Center, Chaoyang District for their assistance in organizing and administrative the work.

\section{References}

1. Saxena S, Setoya Y(2014)World Health Organization's Comprehensive Mental Health Action Plan 20132020.Psychiatry Clin Neurosci 68 (8):585-586. 'doi:'10.1111/pcn.12207

2. Patel V, Xiao S, Chen H, Hanna F, Jotheeswaran AT, Luo D, Parikh R, Sharma E, Usmani S, Yu Y, Druss BG, Saxena S(2016)The magnitude of and health system responses to the mental health treatment gap in adults in India and China.LANCET 388 (10063):3074-3084. 'doi:'10.1016/S0140-6736(16)00160-4 
3. Ma H(2012)Integration of hospital and community services-the '686 Project'-is a crucial component in the reform of China's mental health services.Shanghai Arch Psychiatry 24 (3):172-174.

'doi:'10.3969/j.issn.1002-0829.2012.03.007

4. Zhang W, Ma N(2017)China's National Comprehensive Management Pilot Project for Mental Health.BJPsych Int 14 (2):44-46. 'doi:'10.1192/s2056474000001781

5. Patel V, Saxena S, Lund C, Thornicroft G, Baingana F, Bolton P, Chisholm D, Collins PY, Cooper JL, Eaton J, Herrman H, Herzallah MM, Huang Y, Jordans M, Kleinman A, Medina-Mora ME, Morgan E, Niaz U, Omigbodun O, Prince M, Rahman A, Saraceno B, Sarkar BK, De Silva M, Singh I, Stein DJ, Sunkel C, UnUtzer J(2018)The Lancet Commission on global mental health and sustainable development.LANCET 392 (10157):1553-1598. 'doi:'10.1016/S0140-6736(18)31612-X

6. Li J, Li J, Thornicroft G, Huang Y(2014)Levels of stigma among community mental health staff in Guangzhou, China.BMC PSYCHIATRY 14:231. 'doi:'10.1186/s12888-014-0231-x

7. Thornicroft G(2006)Shunned: Discrimination against People with Mental Illness(Vol.Oxford University Press,0xford

8. Thornicroft G, Rose D, Kassam A, Sartorius N(2007)Stigma: ignorance, prejudice or discrimination?Br J Psychiatry 190:192-193. 'doi:'10.1192/bjp.bp.106.025791

9. Thornicroft G, Brohan E, Rose D, Sartorius N, Leese M(2009)Global pattern of experienced and anticipated discrimination against people with schizophrenia: a cross-sectional survey.LANCET 373 (9661):408-415. 'doi:'10.1016/S0140-6736(08)61817-6

10. Phillips MR, Pearson V, Li F, Xu M, Yang L(2002)Stigma and expressed emotion: a study of people with schizophrenia and their family members in China.Br J Psychiatry 181:488-493. 'doi:'10.1192/bjp.181.6.488

11. Lv Y, Wolf A, Wang X(2013)Experienced stigma and self-stigma in Chinese patients with schizophrenia.Gen Hosp Psychiatry 35 (1):83-88. 'doi:'10.1016/j.genhosppsych.2012.07.007

12. Lam CS, Tsang HWH, Corrigan PW, Lee Y, Angell B, Shi K, Jin S, Larson JE(2010)Chinese lay theory and mental illness stigma: Implications for research and practices.J REHABIL 76 (1):35

13. Lauber C, Nordt C, Braunschweig C, Rossler W(2006)Do mental health professionals stigmatize their patients?Acta Psychiatr Scand Suppl (429):51-59. 'doi:'10.1111/j.1600-0447.2005.00718.x

14. Lasalvia A, Zoppei S, Van Bortel T, Bonetto C, Cristofalo D, Wahlbeck K, Bacle SV, Van Audenhove C, van Weeghel J, Reneses B, Germanavicius A, Economou M, Lanfredi M, Ando S, Sartorius N, Lopez-Ibor JJ, Thornicroft G(2013)Global pattern of experienced and anticipated discrimination reported by people with major depressive disorder: a cross-sectional survey.LANCET 381 (9860):55-62. 'doi:'10.1016/S0140-6736(12)61379-8

15. Henderson C, Noblett J, Parke H, Clement S, Caffrey A, Gale-Grant O, Schulze B, Druss B, Thornicroft $\mathrm{G}(2014)$ Mental health-related stigma in health care and mental health-care settings. LANCET PSYCHIAT 1 (6):467-482. 'doi:'10.1016/S2215-0366(14)00023-6

16. Graber MA, Bergus G, Dawson JD, Wood GB, Levy BT, Levin I(2000)Effect of a patient's psychiatric history on physicians' estimation of probability of disease.J GEN INTERN MED 15 (3):204-206. 'doi:'10.1046/j.1525-1497.2000.04399.x

Page $14 / 17$ 
17. Corrigan PW, Mittal D, Reaves CM, Haynes TF, Han X, Morris S, Sullivan G(2014)Mental health stigma and primary health care decisions.Psychiatry Res 218 (1-2):35-38. 'doi:'10.1016/j.psychres.2014.04.028

18. Liu NH, Daumit GL, Dua T, Aquila R, Charlson F, Cuijpers P, Druss B, Dudek K, Freeman M, Fujii C, Gaebel W, Hegerl U, Levav I, Munk LT, Ma H, Maj M, Elena MM, Nordentoft M, Prabhakaran D, Pratt K, Prince M, Rangaswamy T, Shiers D, Susser E, Thornicroft G, Wahlbeck K, Fekadu WA, Whiteford H, Saxena S(2017)Excess mortality in persons with severe mental disorders: a multilevel intervention framework and priorities for clinical practice, policy and research agendas.WORLD PSYCHIATRY 16 (1):30-40. 'doi:'10.1002/wps.20384

19. Thornicroft G, Mehta N, Clement S, Evans-Lacko S, Doherty M, Rose D, Koschorke M, Shidhaye R, O'Reilly C, Henderson C(2016)Evidence for effective interventions to reduce mental-health-related stigma and discrimination.LANCET 387 (10023):1123-1132. 'doi:'10.1016/S0140-6736(15)00298-6

20. Corrigan PW, Morris SB, Michaels PJ, Rafacz JD, Rusch N(2012)Challenging the public stigma of mental illness: a meta-analysis of outcome studies.Psychiatr Serv 63 (10):963-973. 'doi:'10.1176/appi.ps.201100529

21. Knaak S, Modgill G, Patten SB(2014)Key ingredients of anti-stigma programs for health care providers: a data synthesis of evaluative studies.Can J Psychiatry 59 (10 Suppl 1):S19-S26. 'doi:'10.1177/070674371405901s06

22. Hansson L, Markstrom U(2014)The effectiveness of an anti-stigma intervention in a basic police officer training programme: a controlled study.BMC PSYCHIATRY 14:55. 'doi:'10.1186/1471-244X-14-55

23. Koller M, Stuart H(2016)Reducing stigma in high school youth.Acta Psychiatr Scand 134 Suppl 446:6370. 'doi:'10.1111/acps.12613

24. Wang Y, Wang X, Zhang W, Liang X, Tian D, Qu Z(2017)Risk factors of the stigma towards psychiatric patients among primary healthcare workers in China: a county study.BMC PSYCHIATRY 17 (1):62. 'doi:'10.1186/s12888-017-1215-4

25. Zhu Y, Zhang H, Yang G, Hu X, Liu Z, Guo N, He H, Sun B, Rosenheck R(2018)Attitudes towards mental illness among medical students in China: Impact of medical education on stigma.Asia Pac Psychiatry 10 (2):e12294. 'doi:'10.1111/appy.12294

26. Li J, Li J, Huang Y, Thornicroft G(2014)Mental health training program for community mental health staff in Guangzhou, China: effects on knowledge of mental illness and stigma.INT J MENT HEALTH SY 8 (49). 'doi:'10.1186/1752-4458-8-49

27. Evans-Lacko S, Little K, Meltzer H, Rose D, Rhydderch D, Henderson C, Thornicroft G(2010)Development and psychometric properties of the Mental Health Knowledge Schedule.Can J Psychiatry 55 (7):440-448. 'doi:'10.1177/070674371005500707

28. Kassam A, Glozier N, Leese M, Henderson C, Thornicroft G(2010)Development and responsiveness of a scale to measure clinicians' attitudes to people with mental illness (medical student version). Acta Psychiatr Scand 122 (2):153-161. 'doi:'10.1111/j.1600-0447.2010.01562.x

29. Jie LI, Juan LI, Gabbidon J, Clement S, Zhi-ying MA, Yang-bo G, Thornicroft G(2014)Reliability and validity of the Chinese vision of mental illness:the clinicians's attitudes scale among com-munity mental health staff.J CLIN PSYCHIAT 4:227-229 
30. Evans-Lacko S, Rose D, Little K, Flach C, Rhydderch D, Henderson C, Thornicroft G(2011)Development and psychometric properties of the reported and intended behaviour scale (RIBS): a stigma-related behaviour measure.Epidemiol Psychiatr Sci 20 (3):263-271. 'doi:'10.1017/s2045796011000308

31. Star. (1952). What the public thinks about mental health and mental illness. Paper presented at the Annual meeting of the National Association of Mental Health, Indianapolis, Indiana.

32. Li J, Li J, Thornicroft G, Huang Y(2014)Levels of stigma among community mental health staff in Guangzhou, China.BMC PSYCHIATRY 14:231. 'doi:'10.1186/s12888-014-0231-x

33. Li J, Li J, Thornicroft G, Yang H, Chen W, Huang Y(2015)Training community mental health staff in Guangzhou, China: evaluation of the effect of a new training model.BMC PSYCHIATRY 15:263. 'doi:'10.1186/s12888-015-0660-1

34. Thornicroft G, Mehta N, Clement S, Evans-Lacko S, Doherty M, Rose D, Koschorke M, Shidhaye R, O'Reilly C, Henderson C(2016)Evidence for effective interventions to reduce mental-health-related stigma and discrimination.LANCET 387 (10023):1123-1132. 'doi:'10.1016/S0140-6736(15)00298-6

35. Xu Z, Ruesh N, Huang F, Koesters M(2017)Challenging mental health related stigma in China: Systematic review and meta-analysis. I. Interventions among the general public.PSYCHIAT RES 255:449456. 'doi:'10.1016/j.psychres.2017.01.008

36. Maunder RD, White FA(2019)Intergroup contact and mental health stigma: A comparative effectiveness meta-analysis.CLIN PSYCHOL REV 72:101749. 'doi:'10.1016/j.cpr.2019.101749

37. Pettigrew TF, Tropp LR(2008)How does intergroup contact reduce prejudice? Meta-analytic tests of three mediators.EUR J SOC PSYCHOL 38 (6):922-934

38. Xiong W, Phillips MR(2016)Translated and annotated version of the 2015-2020 National Mental Health Work Plan of the People's Republic of China.Shanghai Arch Psychiatry 28 (1):4-17. 'doi:'10.11919/j.issn.1002-0829.216012

\section{Figures}




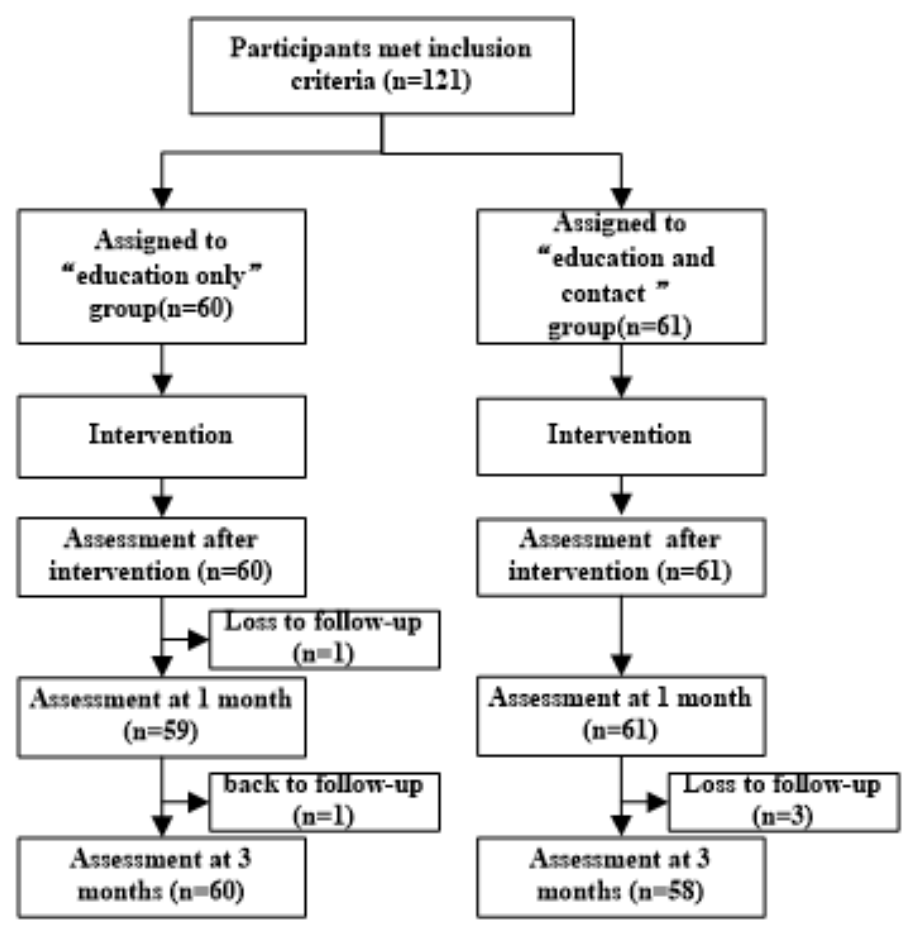

Figure 1

Consort chart for the trial

\section{Supplementary Files}

This is a list of supplementary files associated with this preprint. Click to download.

- CONSORT2010Checklist.doc 